\title{
Erratum to: No clinically significant drug interactions between lenalidomide and P-glycoprotein substrates and inhibitors: results from controlled phase I studies in healthy volunteers
}

\author{
Nianhang Chen · Daniel Weiss · Josephine Reyes • Liangang Liu • \\ Claudia Kasserra · Xiaomin Wang • Simon Zhou • Gondi Kumar • \\ Lilia Weiss · Maria Palmisano
}

Published online: 1 August 2014

(C) Springer-Verlag Berlin Heidelberg 2014

\section{Erratum to: Cancer Chemother Pharmacol (2014) 73:1031-1039 \\ DOI 10.1007/s00280-014-2438-4}

The author would like to correct the errors in the publication of the original article. The corrected details are given below for your reading.

Page 1032, Subjects and methods, Study population: "body mass index of $18-33 \mathrm{~kg} / \mathrm{m}$ [2], aged" should be replaced with "body mass index of $18-33 \mathrm{~kg} / \mathrm{m}^{2}$, aged".

Page 1033, Subjects and methods, Study design and treatment, Evaluation of lenalidomide interactions with temsirolimus: "serial blood samples were collected for 168-h after start of temsirolimus infusion" should be replaced with: "serial blood samples were collected in the first $168 \mathrm{~h}$ after start of temsirolimus infusion".

Page 1033, Subjects and methods, Bioanalytical methodology: "tacrolimus, and [[13] C [2, 3] H7]-temsirolimus were" should be replaced with "tacrolimus, and $\left[{ }^{13} \mathrm{C} 3\right.$, $\left.{ }^{2} \mathrm{H} 7\right]$-temsirolimus, were".

Page 1034, Table 1: The text in the table should be aligned to the left.

The correct Table 1 is given below.

Table 1 Pharmacokinetic parameters of lenalidomide alone and in the presence of digoxin, quinidine, or temsirolimus

\begin{tabular}{|c|c|c|c|c|c|c|}
\hline \multirow[t]{2}{*}{ Pharmacokinetic parameter } & \multicolumn{2}{|c|}{ Lenalidomide (10 mg) } & \multicolumn{2}{|c|}{ Lenalidomide (25 mg) } & \multicolumn{2}{|c|}{ Lenalidomide (25 mg) } \\
\hline & Alone $(n=17)$ & $+\operatorname{Digoxin}(n=17)$ & Alone $(n=14)$ & +Quinidine $(n=14)$ & Alone $(n=17)$ & + Temsirolimus $(n=11)$ \\
\hline $\mathrm{AUC}_{\mathrm{t}}(\mathrm{h} \bullet \mathrm{ng} / \mathrm{mL})$ & $396(32.7)$ & $386(38.9)$ & $1,288(12.1)$ & $1,127(9.6)$ & $1,276(12.0)$ & $1,366(14.5)$ \\
\hline $\mathrm{AUC}_{\infty}(\mathrm{h} \bullet \mathrm{ng} / \mathrm{mL})$ & $475(23.2)$ & $491(22.2)$ & $1,361(12.7)$ & $1,190(9.8)$ & $1,351(11.9)$ & $1,445(14.5)$ \\
\hline$C_{\max }(\mathrm{ng} / \mathrm{mL})$ & $119(20.2)$ & $118(32.8)$ & $367(26.3)$ & $337(12.3)$ & $364(30.0)$ & $361(24.8)$ \\
\hline$T_{\max }(\mathrm{h})$ & $1(1-2)$ & $1(1-2)$ & $1(0.5-3)$ & $1(0.5-1.5)$ & $0.5(0.5-2)$ & $1(1-2)$ \\
\hline$t_{1 / 2}(\mathrm{~h})$ & $2.40(21.0)$ & $2.41(17.0)$ & $2.81(10.1)$ & $2.86(12.9)$ & $2.81(10.5)$ & $2.69(9.1)$ \\
\hline CLR (mL/min) & ND & ND & $227(18.3)$ & $245(11.3)$ & $251(16.4)$ & $229(15.6)$ \\
\hline fe $(\%$ dose $)$ & ND & ND & $74.2(11.4)$ & $70.2(6.6)$ & $81.0(10.0)$ & $79.6(8.0)$ \\
\hline
\end{tabular}

Geometric mean (geometric CV\%) data are presented for all parameters except for $T_{\max }$ where median (range) data are presented

$A U C$ area under the plasma concentration curve, $A U C_{t}$ AUC from time zero to the last measurable concentration, $A U C_{\infty}$ AUC from time zero to infinity, $C L_{R}$ renal clearance, $C_{\max }$ maximum observed plasma concentration; fe, cumulative urinary excretion as a percentage of administered dose, $N D$ not determined, $t_{1 / 2} \mathrm{z}$ terminal-phase half-life, $T_{\text {max }}$ time to reach $C_{\max }$

The online version of the original article can be found under doi:10.1007/s00280-014-2438-4.

N. Chen $(\bowtie) \cdot$ D. Weiss $\cdot$ J. Reyes $\cdot$ L. Liu $\cdot$ C. Kasserra

X. Wang - S. Zhou $\cdot$ G. Kumar $\cdot$ L. Weiss $\cdot$ M. Palmisano

Celgene Corporation, 86 Morris Avenue, Summit, NJ 07920,

USA

e-mail: nchen@celgene.com 
Page 1035, Figure 2A: "Quiridine" should be replaced with "Quinidine".

Page 1035, Figure 2B: "Quiridine" should be replaced with "Sirolimus".

The correct Fig. 2 is given below.

A

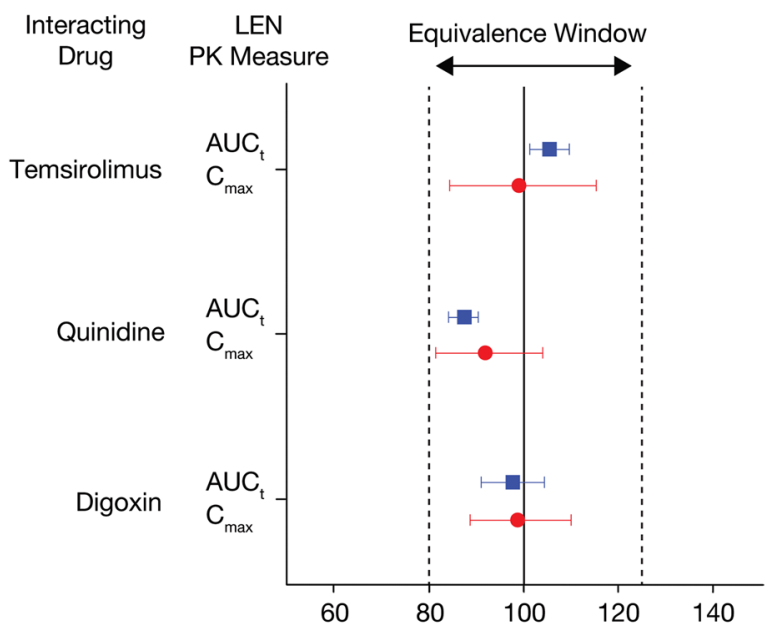

Ratio of Geometric Means and 90\% C (relative to the absence of an interacting drug)
B

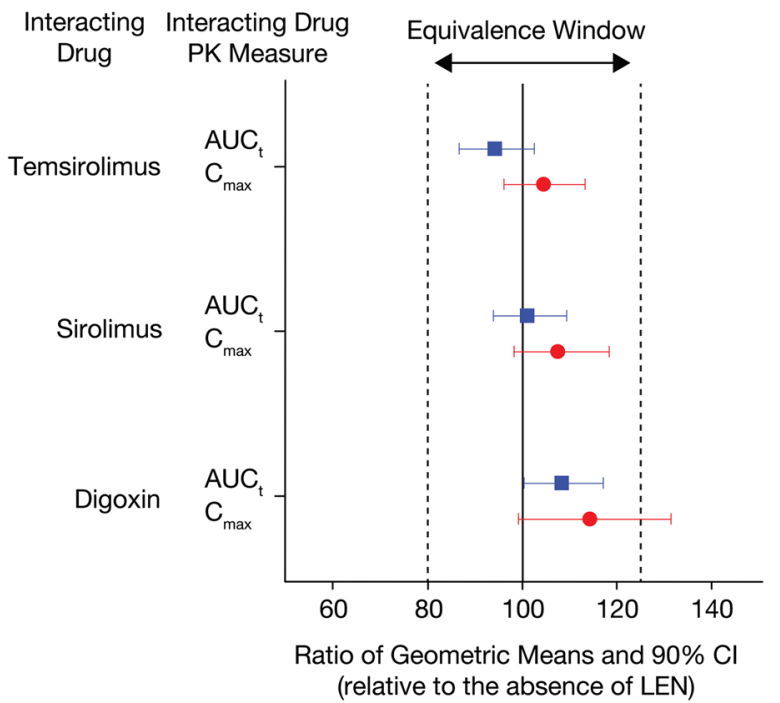

Fig. 2 Ratio of geometric means and associated $90 \%$ confidence interval for systemic exposure $\left(C_{\max }\right.$ and $\left.\mathrm{AUC}_{\mathrm{t}}\right)$ of lenalidomide (a) and interacting drugs (b) when co-administered

Page 1035, Figure 3B: "LEN + temsiroliums" should be replaced with "LEN + temsirolimus".

The correct Fig. 3 is given below.
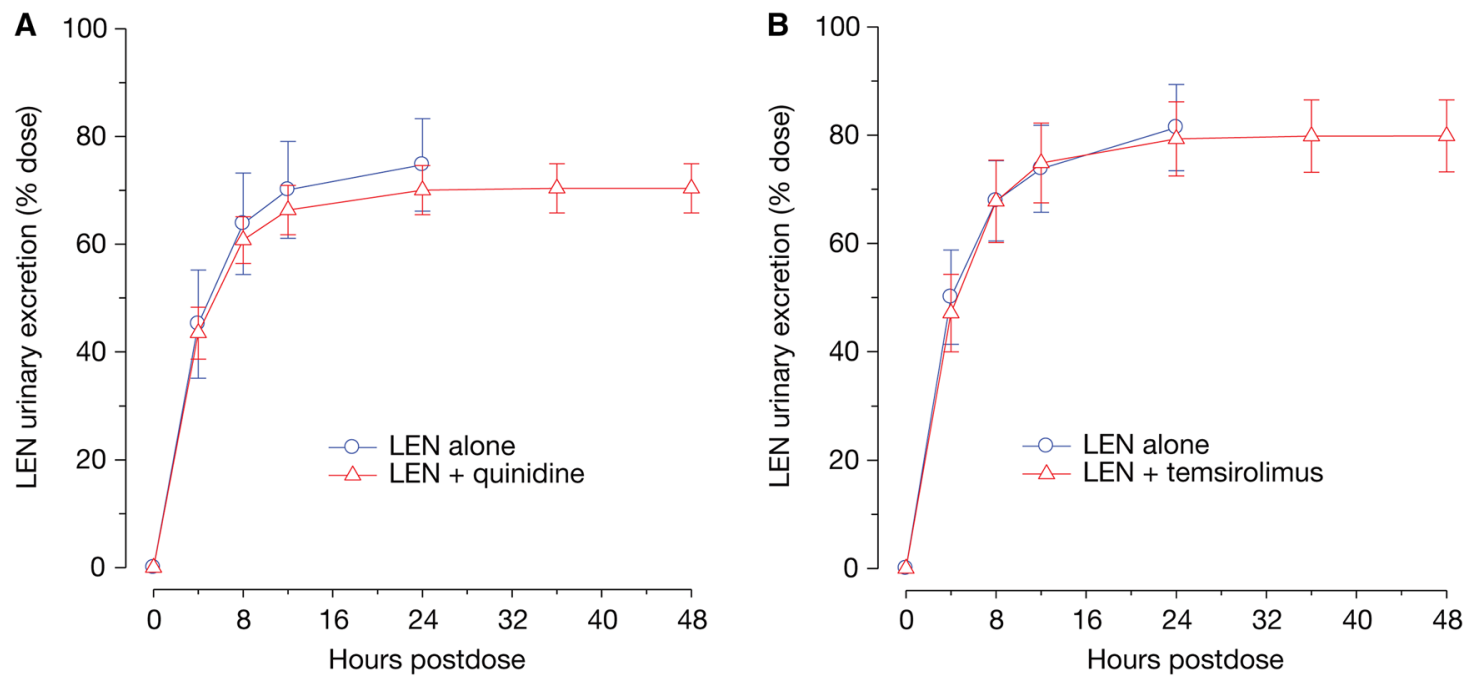

Fig. 3 Mean ( \pm standard deviation) renal excretion-time profile of lenalidomide alone and in the presence of (a) quinidine or (b) temsirolimus in healthy subjects

Page 1036, Figure 4, legend: "absence and presence of lenalidoimide" should be replaced with "absence or presence of lenalidomide". 